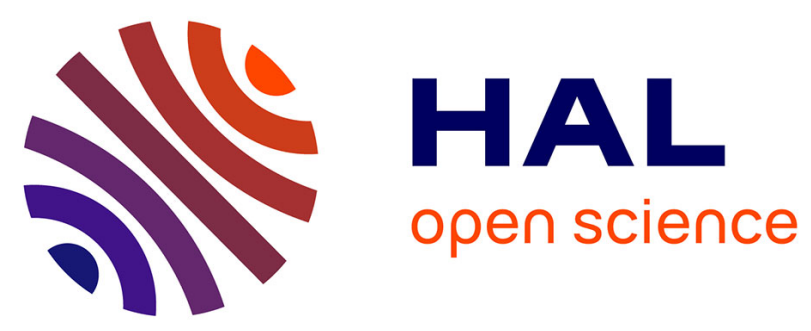

\title{
Continuous-wave and femtosecond laser operation of Yb:CaGdAlO4 under high-power diode pumping
}

Justine Boudeile, Frédéric Druon, Marc Hanna, Patrick Georges, Yoann

Zaouter, Eric Cormier, J. Petit, Philippe Goldner, Bruno Viana

\section{To cite this version:}

Justine Boudeile, Frédéric Druon, Marc Hanna, Patrick Georges, Yoann Zaouter, et al.. Continuouswave and femtosecond laser operation of $\mathrm{Yb}: \mathrm{CaGdAlO} 4$ under high-power diode pumping. Optics Letters, 2007, 32 (14), pp.1962-1964. hal-00700690

\section{HAL Id: hal-00700690 \\ https://hal-iogs.archives-ouvertes.fr/hal-00700690}

Submitted on 23 May 2012

HAL is a multi-disciplinary open access archive for the deposit and dissemination of scientific research documents, whether they are published or not. The documents may come from teaching and research institutions in France or abroad, or from public or private research centers.
L'archive ouverte pluridisciplinaire HAL, est destinée au dépôt et à la diffusion de documents scientifiques de niveau recherche, publiés ou non, émanant des établissements d'enseignement et de recherche français ou étrangers, des laboratoires publics ou privés. 


\title{
Continuous-wave and femtosecond laser operation of $\mathrm{Yb}: \mathrm{CaGdAlO}_{4}$ under high-power diode pumping
}

\author{
J. Boudeile, ${ }^{1, *}$ F. Druon, ${ }^{1}$ M. Hanna,,${ }^{1}$ P. Georges,${ }^{1}$ Y. Zaouter, ${ }^{2}$ E. Cormier, ${ }^{2}$ J. Petit, ${ }^{3}$ P. Goldner,${ }^{3}$ and \\ B. Viana ${ }^{3}$ \\ ${ }^{1}$ Laboratoire Charles Fabry de l'Institut d'Optique, CNRS, Univ Paris-Sud, Campus Polytechnique, RD 128, 91127 \\ Palaiseau Cedex, France \\ ${ }^{2}$ Amplitude Systèmes, Allée du Doyen Georges Brus 33600 Pessac-France \\ ${ }^{3}$ Laboratoire de Chimie Appliquée de l'Ecole Nationale Supérieure de Chimie de Paris, 11 Rue P. et M. Curie, 75231 \\ Paris Cedex 05, France \\ *Corresponding author: justine.boudeile@institutoptique.fr
}

Received April 2, 2007; revised May 10, 2007; accepted May 15, 2007; posted May 17, 2007 (Doc. ID 81748); published July 2, 2007

We demonstrate the generation of $68 \mathrm{fs}$ secant hyperbolic pulses at a $105 \mathrm{MHz}$ repetition rate with an average power of $520 \mathrm{~mW}$ from a diode-pumped $\mathrm{Yb}^{3+}: \mathrm{CaGdAlO}_{4}$ mode-locked laser. A semiconductor saturable absorber allows passive mode locking, and a $15 \mathrm{~W}$ diode laser is used to pump directly the crystal. To our knowledge this represents the highest average power ever obtained for a sub-100 fs diode-pumped Yb-bulk laser. (C) 2007 Optical Society of America

OCIS codes: $140.5680,140.3480,140.4050$.

More and more scientific and industrial applications require the development of efficient femtosecond lasers. Laser systems based on diode-pumped $\mathrm{Yb}^{3+}$-doped bulk materials are promising in this respect, because of the very simple spectroscopic properties of Yb, its weak quantum defect, the lack of undesired effects such as upconversion or concentration quenching, and above all the possibility to use highpower diodes to pump these materials. In the past decade, many crystals were proposed for a new generation of femtosecond diode-pumped solid-state lasers. On the one hand, femtosecond lasers based on orthosilicate crystals such as $\mathrm{Yb}: \mathrm{YSO}[1]\left(\mathrm{Yb}^{3+}: \mathrm{Y}_{2} \mathrm{SiO}_{5}\right)$ and $\mathrm{Yb}: \mathrm{LuSO}$ [1] $\left(\mathrm{Yb}^{3+}: \mathrm{Lu}_{2} \mathrm{SiO}_{5}\right)$ or the crystals $\mathrm{Yb}: \mathrm{KYW}[2]\left(\mathrm{Yb}^{3+}: \mathrm{KY}\left(\mathrm{WO}_{4}\right)_{2}\right)$ and $\mathrm{Yb}: \mathrm{KGW}[3,4]$ $\left(\mathrm{Yb}: \mathrm{KGd}\left(\mathrm{WO}_{4}\right)_{2}\right)$ have demonstrated high average powers. However, achievable pulse widths are $\geqslant 100 \mathrm{fs}$. On the other hand, sub-100-fs pulses were obtained with $\mathrm{Yb}: \mathrm{BOYS}$ [5] $\left(\mathrm{Yb}^{3+}: \mathrm{Sr}_{3} \mathrm{Y}\left(\mathrm{BO}_{3}\right)_{3}\right)$ or $\mathrm{Yb}: \mathrm{SYS}[6]\left(\mathrm{Yb}^{3+}: \mathrm{SrY}_{4}\left(\mathrm{SiO}_{4}\right)_{3} \mathrm{O}\right)$. But, because of a poor thermal conductivity (less than $2 \mathrm{~W} / \mathrm{m} / \mathrm{K}$ ), these crystals are not able to sustain high-power pumping, typically higher than $10 \mathrm{~W}$. Consequently, these crystals cannot deliver high average output powers in standard oscillator configurations. This shows that a combination of high average power and ultrashort pulses is still a challenge for diodepumped lasers based on Yb-doped crystal.

A new generation of crystal is now emerging to compensate for this lack with both high conductivities (higher than $6 \mathrm{~W} / \mathrm{m} / \mathrm{K}$ ) and flat and smooth spectra. First, crystals of the vanadate family such as $\mathrm{Yb}: \mathrm{YVO}_{4}[7,8], \mathrm{Yb}: \mathrm{GdVO}_{4}$ [9], and $\mathrm{Yb}: \mathrm{LuVO}_{4}$ [10] exhibit an emission spectrum shape very similar to $\mathrm{Yb}$-doped glasses and have been used to generate pulses as short as $61 \mathrm{fs}$. Moreover, a laser based on $\mathrm{Yb}: \mathrm{GdVO}_{4}$ has been demonstrated under $50 \mathrm{~W}$ diode pumping without damage and with an output power in the $\mathrm{CW}$ regime of $4 \mathrm{~W}$ [11]. Second, the Yb:CALGO $\left(\mathrm{Yb}^{3+}: \mathrm{CaGdAlO}_{4}\right)$ crystal is also very attractive because of its atypical broad and flat emission bandwidth, which is propitious for the generation of ultrashort pulses. Recently, this crystal was used to demonstrate the generation of $47 \mathrm{fs}$ pulses with a low-power diode pumping of $5 \mathrm{~W}$ and an average output power of $38 \mathrm{~mW}$ [12]. In this Letter, we propose to study the performance of this crystal under higherpower diode pumping in both the CW and the femtosecond regimes.

In the CALGO crystal structure, $\mathrm{Ca}^{2+}$ and $\mathrm{Gd}^{3+}$ equally share the same crystallographic site and can both be substituted with $\mathrm{Yb}^{3+}$ ions. Even if $\mathrm{Ca}^{2+}$ and $\mathrm{Gd}^{3+}$ ions have the same crystallographic site, $\mathrm{Gd}^{3+}$ substitution is strongly predominant because of the same valence of the $\mathrm{Yb}^{3+}$ and $\mathrm{Gd}^{3+}$ ions. This leads to the large inhomogeneous broadening observed in the emission spectrum [Fig. 1(a)]. The presence of a plateau in the gain cross section between 1000 and $1050 \mathrm{~nm}$ can be explained by the complementarity of two different sites in the host. A selective excitation experiment at low temperature was carried out to check this assumption. At $10 \mathrm{~K}$, for pump wavelengths of 978 and $983 \mathrm{~nm}$, two complementary emis-
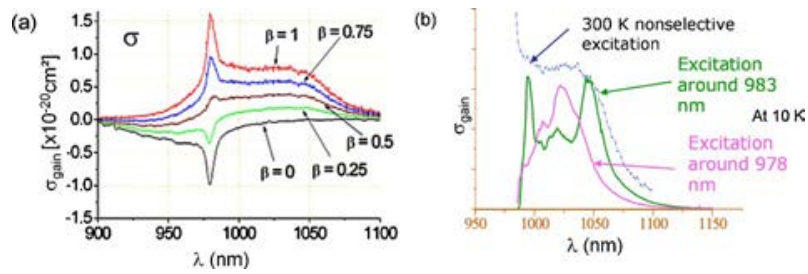

Fig. 1. (Color online) (a) Emission spectra. $\beta$ is the population inversion. For $\beta=0$ and $\beta=1, \sigma_{\text {gain }}$ corresponds to the absorption and emission cross sections, respectively. (b) Emission spectra obtained by selective excitation at $10 \mathrm{~K}$ and room temperature. 


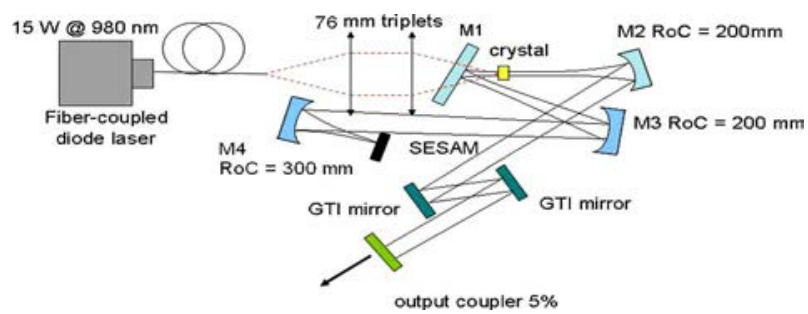

Fig. 2. (Color online) Laser cavity design in the femtosecond regime.

sion spectra corresponding to different sites are observed [Fig. 1(b)]. So, for a pump wavelength excitation inferior to $980 \mathrm{~nm}$, a site is excited; the opposite is the case for a pump wavelength excitation superior to $980 \mathrm{~nm}$. But, at room temperature $(300 \mathrm{~K})$ and when the pump wavelength is around $980 \mathrm{~nm}$, there is no selective excitation and the phenomenon is noticed only because of the presence of only one spectrum [Fig. 1(b)]. This peculiarity explains the unusually flat emission spectrum of CALGO.

A recently presented model [13] allowed us to evaluate the thermal conductivity of undoped $\mathrm{CaGdAlO}_{4}$ at $11.4 \mathrm{~W} \mathrm{~K}^{-1} \mathrm{~m}^{-1}$. To minimize the thermal conductivity decrease with doping, the mass of the dopant should be as close as possible to the mass of substituted ions. For $\mathrm{Yb}$ :CALGO, this is indeed the case since the mass difference between gadolinium and ytterbium cations is less than $10 \%$. Measurements of the 2 at. \% Yb:CALGO thermal conductivity yielded 6.9 and $6.3 \mathrm{~W} \mathrm{~K}^{-1} \mathrm{~m}^{-1}$ along the $a$ and $c$ axis, respectively. This is similar to values obtained in $\mathrm{Yb}$ :YAG for $8 \% \mathrm{Yb}^{3+}$ doping [14]. A flat, smooth, and board emission spectrum and an excellent thermal conductivity of the $\mathrm{Yb}^{3+}: \mathrm{CaGdAlO}_{4}$ are responsible for a potential combination of high average power and ultrashort laser pulses.

The laser experiment was performed with a $2.5 \mathrm{~mm}$, antireflection-antireflection coated, 2 at. \% $\mathrm{Yb}^{3+}: \mathrm{CaGdAlO}_{4}$ directly pumped by a $15 \mathrm{~W}$ fibercoupled diode laser (LIMO) with a $100 \mu \mathrm{m}$ core diameter and a numerical aperture of 0.22 . The wavelength of the diode is adjusted to the maximum of absorption of the Yb:CALGO at $979.5 \mathrm{~nm}$. The absorption of the crystal at this wavelength is only $50 \%$. The pump beam is collimated and focused into the gain medium using $76 \mathrm{~mm}$ focal-length triplets. The crystal is contacted to a thick indium foil and placed on a water-cooled copper mount.

The crystal was first tested in a simple CW configuration. The laser cavity design is composed of a plane mirror, a $200 \mathrm{~mm}$ radius of curvature mirror, and a plane output coupler. To maximize the output power, couplers with a transmission of $1 \%, 2 \%, 4 \%$, and $6 \%$ were tested. With a $15 \mathrm{~W}$ incident pump power, the output average power is $1.7,2.23,2.3$, and $1.97 \mathrm{~W}$, respectively, with corresponding threshold values of $1.6,1.7,2$, and $3 \mathrm{~W}$. The slope efficiency with a $4 \%$ output coupler (output power versus diode power) is $18.4 \%$, and the optical-optical efficiency is $15.3 \%$, which corresponds to $25.5 \%$ of optical efficiency versus absorbed pump power.
The laser cavity design for the femtosecond regime is shown in Fig. 2. The laser beam diameter in the $\mathrm{Yb}$ :CALGO is set to $60 \mu \mathrm{m}$ using two mirrors of $200 \mathrm{~mm}$ radius of curvature. Two Gires-Tournois interferometers (GTIs, or negative-dispersion mirrors) providing a negative dispersion of $-550 \mathrm{fs}^{2}$ each are inserted inside the cavity to compensate the dispersion introduced by the crystal. Furthermore, a semiconductor saturable absorber mirror (SESAM) designed to operate at the wavelength of $1040 \mathrm{~nm}$ is used to initiate and stabilize the passive mode-locked regime. Owing to the long lifetime of the $\mathrm{Yb}$-doped crystals, the laser is susceptible to $Q$-switching instabilities. Therefore, care was taken in the choice of the SESAM [15]. For optimization, different SESAMs from two companies (Batop and AmplitudeSystemes) were tested with a systematic SESAM spot size optimization (waists from 25 to $100 \mu \mathrm{m}$ ) to adjust the laser fluence. The SESAM modulation depths were between $0.5 \%$ to $2 \%$, and the saturation fluence was $>120 \mu \mathrm{J} \mathrm{cm}^{-2}$ for the Amplitude SESAMs and equal to $70 \mu \mathrm{J} \mathrm{cm}^{-2}$ for the Batop SESAMs. This procedure was undertaken to find the optimum of stability and pulse duration. With the low modulation depth SESAM (0.5\%) no mode-locked regime was observed. Concerning the stability, better results were obtained with the $1 \%$ than with the $2 \%$, as expected [15]. In terms of pulse duration, generation of sub-100-fs pulses was obtained only with the Amplitude-Systemes SESAMs, In fact, we were limited by double pulsing occurrence for longer pulses in the case of Batop SESAM than in the case of the Amplitude SESAM. This can be attributed to the fact that the reflectivity versus wavelength varies from one SESAM to another [16]. In our case, the Amplitude SESAM seems more appropriate to the emission curve shape of Yb:CALGO. The best results were obtained with $1 \%$ modulation-depth Amplitude SESAM for a $46 \mu \mathrm{m}$ spot size on the SESAM (using a $300 \mathrm{~mm}$ radius of curvature mirror).

To avoid problems related to the SESAM, we investigated the potential of using Kerr lens mode locking $[17,18]$ by measuring the nonlinear index $\left(n_{2}\right)$. The nonlinear index of CALGO was evaluated in a long

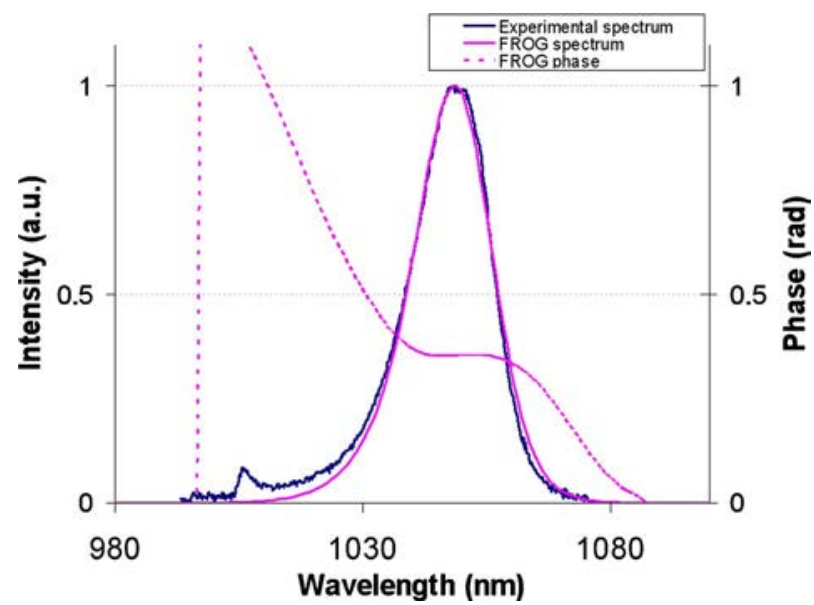

Fig. 3. (Color online) Directly measured spectrum (jagged solid curve) and spectral intensity and phase retrieved from the FROG trace (smooth solid curve, dashed curve). 


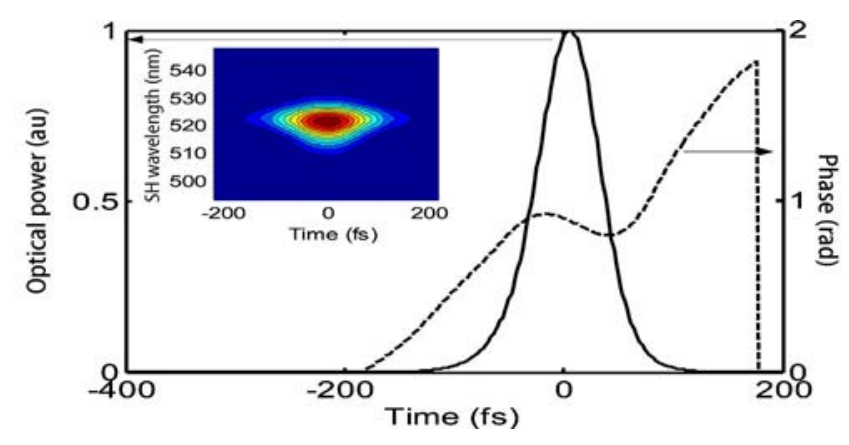

Fig. 4. (Color online) Temporal profile (solid line) and phase (dashed line) retrieved from the FROG trace (inset).

cavity $(8 \mathrm{~m})$ that was very sensitive to geometrical modifications, e.g., to the Kerr lens. We measured the waist difference at the output of the laser in the $\mathrm{CW}$ and mode-locked regimes for constant pump power to avoid the influence of thermal lens. We measured a waist variation of $3.7 \%$, corresponding to a $\delta_{1}$ parameter [19] of 2.16 and $n_{2}=9 \times 10^{-7} \mathrm{~cm}^{2} / \mathrm{GW}$.

In previously reported experiments, the output pulses were not Fourier transform-limited, and an extracavity SF10-prism-based compressor was necessary to compensate the residual dispersion [11]. In this experiment, to remove additional sources of group velocity dispersion (GVD), all the mirrors in the cavity (except the dichroic mirrors) were replaced with low GVD $\left(<20 \mathrm{fs}^{2}\right)$ mirrors.

Passive mode-locked operation is achieved at a repetition rate of $105 \mathrm{MHz}$. The spectrum, measured with a spectrometer, is shown in Fig. 3 . It is centered at $1050 \mathrm{~nm}$ and exhibits a full-width maximum of $18.5 \mathrm{~nm}$. We notice a secondary peak centered around $1007 \mathrm{~nm}$ on the short wavelength side of the spectrum. This wavelength corresponds to the cutoff wavelength of the dichroic mirror present in the cavity. To obtain a stable mode-locked regime, the output average power must exceed $140 \mathrm{~mW}$, corresponding to an intracavity power of $7 \mathrm{~W}$.

A frequency-resolved optical gating (FROG) setup based on second-harmonic generation was used to fully characterize the output pulses. The FROG trace is shown in Fig. 4, along with the retrieved field in the temporal domain. The retrieved spectrum and spectral phase are plotted in Fig. 3. A good agreement with the independently measured spectrum is observed. The second, third, and fourth derivatives of the phase with respect to the angular frequency were measured to be $-33 \mathrm{fs}^{2},-3.05 \times 10^{-41} \mathrm{~s}^{3}$, and 5.3 $\times 10^{-55} \mathrm{~s}^{4}$, respectively. These values are derived from a fit that depends on the center wavelength chosen at $1050 \mathrm{~nm}$. This wavelength corresponds to the wavelength at the maximum of the spectrum. The second-order phase, corresponding to GVD, is weak and the cavity operates near the soliton regime. The use of low-GVD mirrors therefore allowed us to sup- press efficiently the residual quadratic chirp. The cubic spectral phase is now the dominant spectral aberration. The temporal profile (Fig. 4) shows a hyperbolic secant pulse, with a pulse width of $68 \mathrm{fs}$. The time-bandwidth product is 0.34 . Finally, the average power is $520 \mathrm{~mW}$ with a $15 \mathrm{~W}$ incident pump power for a repetition rate of $105 \mathrm{MHz}$ and with a $5 \%$ output coupler. This corresponds to an energy per pulse of $5 \mathrm{~nJ}$ or $64 \mathrm{~kW}$ peak power.

In conclusion, we demonstrated the generation of $68 \mathrm{fs}$ pulses centered at $1050 \mathrm{~nm}$ with a 2 at. \%, $2.5 \mathrm{~mm}$ long $\mathrm{Yb}: \mathrm{CaGdAlO}_{4}$ crystal. The laser average power is $520 \mathrm{~mW}$. This is, to our knowledge, the highest average power reported for a diode-pumped solid-state sub-100-fs laser.

\section{References}

1. F. Thibault, D. Pelenc, F. Druon, Y. Zaouter, M. Jacquemet, and P. Georges, Opt. Lett. 31, 1555 (2006).

2. A. Lagatsky, C. Brown, and W. Sibbett, Opt. Express 12, 3928 (2004).

3. G. R. Holtom, Opt. Lett. 31, 2719 (2006).

4. G. Paunescu, J. Hein, and R. Sauerbrey, Appl. Phys. B 79, 555 (2004).

5. F. Druon, S. Chenais, and P. Raybaut, Appl. Phys. B 74, S201 (2002).

6. F. Druon, F. Balembois, and P. Georges, Opt. Express 12, 5005 (2004).

7. V. E. Kisel, A. E. Troshin, V. G. Shcherbitsky, N. V. Kuleshov, V. N. Matrosov, T. A. Matrosova, M. I. Kupchenko, F. Brunner, R. Paschotta, F. MorierGenoud, and U. Keller, Opt. Lett. 30, 1150 (2005).

8. A. Lagatsky, A. R. Sarmani, C. T. A. Brown, W. Sibbett, V. E. Kisel, A. G. Selivanov, I. A. Denisov, A. E. Troshin, K. V. Yumashev, N. V. Kuleshov, V. N. Matrosov, T. A. Matrosova, and M. I. Kupchenko, Opt. Lett. 30, 3234 (2005).

9. J. Petit, B. Viana, P. Goldner, D. Vivien, P. Louiseau, and B. Ferrand, Opt. Lett. 29, 833 (2004).

10. S. Rivier, X. Mateos, J. Liu, V. Petrov, U. Griebner, M. Zorn, M. Weyers, H. Zhang, J. Wang, and M. Jiang, Opt. Express 14, 11668 (2006).

11. J. Liu, X. Mateos, H. Zhang, J. Wang, M. Jiang, U. Griebner, and V. Petrov, Opt. Lett. 31, 2580 (2006).

12. Y. Zaouter, J. Didierjean, F. Balembois, G. L. Leclin, F. Druon, P. Georges, J. Petit, P. Goldner, and B. Viana, Opt. Lett. 31, 119 (2006).

13. R. Gaumé, B. Viana, D. Vivien, J. P. Roger, and D. Fournie, Appl. Phys. Lett. 83, 1355 (2003).

14. S. Chénais, F. Druon, S. Forget, F. Balembois, P. Georges, Prog. Quantum Electron. 30, 89 (2006).

15. C. Honninger, R. Paschotta, F. Morier-Genoud, M. Moser, and U. Keller, J. Opt. Soc. Am. B 16, 46 (1999).

16. http://www.batop.de/.

17. H. Liu, J. Nees, and G. Mourou, Opt. Lett. 26, 1723 (2001)

18. U. Griebner, S. Rivier, V. Petrov, M. Zorn, G. Erbert, M. Weyers, X. Mateos, M. Aguiló, J. Massons, and F. Díaz, Opt. Express 13, 3465 (2005).

19. G. Cerullo, S. De Silvestri, and V. Magni, Opt. Lett. 19, 1040 (1994). 